\title{
Os sistemas de manejo dos agroecossistemas do Alto Solimões - Amazonas e sua influência na fertilidade dos solos
}

\author{
The management systems of the agroecosystems of the Alto Solimões - Amazonas and its influence \\ on soil fertility \\ Los sistemas de gestión de los agroecosistemas de lo Altos Solimões - Amazonas y su influencia en la \\ fertilidad del suelo
}

Recebido: 03/06/2021 | Revisado: 16/06/2021 | Aceito: 21/06/2021 | Publicado: 05/07/2021

\author{
Marcileia Couteiro Lopes \\ ORCID: https://orcid.org/0000-0002-7953-5336 \\ Universidade Federal do Amazonas, Brasil \\ E-mail: mlopes@ufam.edu.br \\ Hiroshi Noda \\ ORCID: https://orcid.org/0000-0002-3514-1706 \\ Instituto Nacional de Pesquisas da Amazônia, Brasil \\ E-mail: hnoda@inpa.gov.br \\ Marcos Ely Nascimento Fermin \\ ORCID: https://orcid.org/0000-0002-4326-0940 \\ Instituto Natureza e Cultura, Brasil \\ E-mail: marcoselynascimentofermin@gmail.com
}

\begin{abstract}
Resumo
Este estudo foi realizado nos agroecossistemas amazônicos de comunidades do Alto Rio Solimões, sudoeste do Estado do Amazonas. O objetivo foi apresentar a ação das formas de uso e manejo dos solos desenvolvidas pelos agricultores familiares na fertilidade em componentes estabelecidos como: quintal, roças, capoeiras (pousio) e florestas dos agroecossistemas existentes. Foram escolhidas aleatoriamente duas comunidades de agricultores familiares no município de Benjamin Constant, uma em área de várzea, denominada São José e outra em terra firme, denominada Nova Aliança. A análise estatística utilizada teve como delineamento, o blocos ao acaso com quatro repetições cada, onde as parcelas foram relacionadas com os componentes dos agroecossistemas (quintal, roça, capoeira e floresta) e as profundidades relacionadas como sub-parcelas. Por influência do teor de matéria orgânica na superfície, os resultados obtidos nos mostram que dependendo da cobertura vegetal e do tipo de solo, a concentração de nutrientes é maior nas profundidades menores, sendo essencial para a conservação destes solos. Os resultados também demonstram que as formas de manejo adotadas pelos agricultores familiares, modificando as paisagens a partir do seu cotidiano de vida e trabalho, tem efeito na fertilidade dos solos.
\end{abstract}

Palavras-chave: Amazônia; Agricultores familiares; Sustentabilidade.

\begin{abstract}
His study was carried out in the Amazon agroecosystems of communities in the Alto Rio Solimões, southwest of the State of Amazonas. The objective was to present the action of the forms of use and management of soils developed by family farmers in terms of fertility in established components such as: backyards, farmlands, capoeiras (fallow) and forests of existing agroecosystems. Two communities of family farmers in the municipality of Benjamin Constant were randomly chosen, one in a lowland area, called São José, and another in terra firme, called Nova Aliança. The statistical analysis used had a randomized block design with four replications each, where the plots were related to the components of the agroecosystems (backyard, farmland, capoeira and forest) and the depths were related as sub-plots. Due to the influence of the organic matter content on the surface, the results obtained show us that depending on the vegetation cover and the type of soil, the concentration of nutrients is greater in the smaller depths, being essential for the conservation of these soils. The results also demonstrate that the forms of management adopted by family farmers, modifying landscapes based on their daily life and work, have an effect on soil fertility.
\end{abstract}

Keywords: Amazon; Family farmers; Sustainability.

\section{Resumen}

Este estudio se llevó a cabo en los agroecosistemas amazónicos de comunidades del Alto Río Solimões, al suroeste del Estado de Amazonas. El objetivo fue presentar la acción de las formas de uso y manejo de los suelos desarrollados por los agricultores familiares en términos de fertilidad en componentes establecidos tales como: traspatios, rozas, capoeiras (barbechos) y bosques de agroecosistemas existentes. Se eligieron al azar dos comunidades de agricultores familiares 
en el municipio de Benjamin Constant, una en la zona de tierras bajas, denominada São José, y otra en tierra firme, denominada Nova Aliança. El análisis estadístico utilizado tuvo un diseño de bloques al azar con cuatro repeticiones cada uno, donde las parcelas se relacionaron con los componentes de los agroecosistemas (traspatio, campo, capoeiras y bosque) y las profundidades se relacionaron con las subparcelas. Debido a la influencia del contenido de materia orgánica en la superficie, los resultados obtenidos nos muestran que dependiendo de la cobertura vegetal y el tipo de suelo, la concentración de nutrientes es mayor en las profundidades menores, siendo fundamental para la conservación de estos suelos. Los resultados también demuestran que las formas de manejo adoptadas por los agricultores familiares, modificando los paisajes en función de su vida diaria y su trabajo, inciden en la fertilidad del suelo.

Palabras clave: Amazonia; Agricultores familiares; Sustentabilidad.

\section{Introdução}

Na Amazônia, a conservação relaciona-se principalmente com os saberes e com as estratégias adotadas pelas populações locais no uso e manejo do ambiente. O conhecimento e as práxis dos agricultores familiares sobre o uso da terra são instrumentos promotores da conservação do ambiente e da sustentabilidade devido o mínimo impacto sobre o solo e sobre as áreas de florestas nativas remanescentes.

No Alto Rio Solimões, município de Benjamin Constant, Estado do Amazonas, os agricultores familiares manejam dois tipos de paisagens predominantes. As várzeas, áreas mais baixas, suscetíveis a alagação e as terras firmes, em platôs mais elevados, onde predominam solos mais novos, formados a partir de sedimentos quaternários. Nas terras firmes, em geral, os solos são mais evoluídos, formados a partir de sedimentos ou rochas do terciário ou ainda mais antigos. Essas diferentes formações pedológicas, tem características peculiares, no qual uma é mais rica em nutrientes devido deposição contínua e outra mais pobre, dependente da densa vegetação que se estabelece na superfície (Lima, Teixeira e Souza, 2007).

Quanto a geomoforlogia dos solos que ocorrem no Alto Solimões, um estudo da Embrapa Solos, liderado por Coelho et al. em 2005, descreveu a existência de Argissolos e Cambissolos nos platôs e na planície aluvial (várzea) dos rios de águas brancas, predominam os Gleissolos e Neossolos. De acordo com os autores, as classes dos Cambissolos e Argissolos comportam desde solos fortemente até imperfeitamente drenados, de rasos a profundos, de alta a baixa saturação por bases e atividade química da fração coloidal. Já, os Gleissolos e Neossolos são solos que ocupam as partes depressionais da paisagem e, como tal, estão permanentemente ou periodicamente encharcados.

No Alto Solimões, a consciência de conservação ambiental dos agricultores direciona, limita ou condiciona os cultivos agrícolas, a produção e a diversidade, dependendo em qual ecossistema está inserido: se várzea ou terra firme. Toda essa consciência é construída nos processos voltados para a sobrevivência das famílias. Assim sendo, os agricultores familiares ocupam esses espaços nas várzeas e terras firmes com sua produção, na extração de produtos das florestas e capoeiras e com as atividades de pesca. Os produtos obtidos destinam-se exclusivamente ao consumo do núcleo familiar, o excedente produzido é comercializado para aquisição do que não é produzido e serviços não existentes na comunidade, estabelecendo-se então uma relação sustentável única e específica com o ambiente em que vivem (Noda et. al., 2013, p 52).

Neste sistema de manejo dos solos destas áreas, as paisagens são modificadas, compondo assim os agroecossistemas familiares e seus componentes (quintal, roças, capoeiras e florestas), traduzidos por Brandão (2016), como a práxis transformadora das paisagens por meio da agricultura familiar constituídos por unidades de trabalho e produção dentro do sistema ambiental.

Em todos os componentes dos agroecossistemas: roça, quintal, capoeira e floresta, o solo é considerado pelos agricultores um bem comum (termo utilizado por Ricoveri em 2012), no qual, por meio dele, os agricultores expressam seu saber no desenvolvimento de estratégias de uso. Portanto, neste trabalho, pressupôs-se que as práticas de manejo desenvolvidas pelos agricultores auxiliam na incorporação de nutrientes e fertilidade dos solos no Alto Solimões. Nesse sentido, para avaliar se as formas de uso do solo promovem a sustentabilidade das áreas de várzea e terra firme manejadas pelos agricultores em suas dinâmicas de vida e trabalho, assim como, influenciam na concentração de nutrientes nos solos, a pesquisa se propôs verificar 
os teores de nutrientes nos solos dos agroecossistemas familiares das comunidades São José e Nova Aliança, em Benjamin Constant/AM, Alto Rio Solimões.

\section{Metodologia}

O estudo foi realizado no município de Benjamin Constant/AM (4²2' 48.2" S e 70 1'31.8" W) distante $1.116 \mathrm{~km}$ da capital Manaus, mesorregião do Sudoeste do Estado do Amazonas, na tríplice fronteira entre o Brasil, Peru e a Colômbia. A economia do município é voltada principalmente para atividades como o extrativismo vegetal, animal e produção agrícola. De acordo com o Censo Agropecuário do IBGE em 2017, aproximadamente 65\% da população do município está envolvida na agricultura familiar. Boa parte da agricultura é de várzea, sob a influência sazonal do regime hidrológico caracterizado pelos períodos de cheias e secas, assim como pela variação na intensidade das chuvas (Schor, 2015, p. 89-109; IBGE, 2017).

Benjamin Constant possui 59 comunidades rurais, das quais 39 são ribeirinhas e 20 são indígenas (IBGE, 2000). Para esta pesquisa foram selecionadas duas comunidades rurais: São José, na várzea, distante cerca de $9 \mathrm{~km}$ da sede (coordenadas

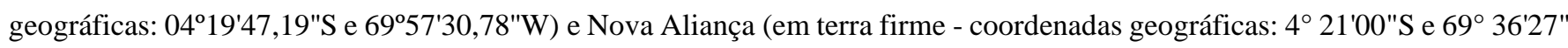
W), cerca de $47 \mathrm{~km}$ de Benjamin Constant. Os agroecossistemas destas duas comunidades foram nossas fontes diretas de coletas de dados (Figura 1).

Figura 1. Representação cartográfica das áreas de estudo em Benjamin Constant - AM.

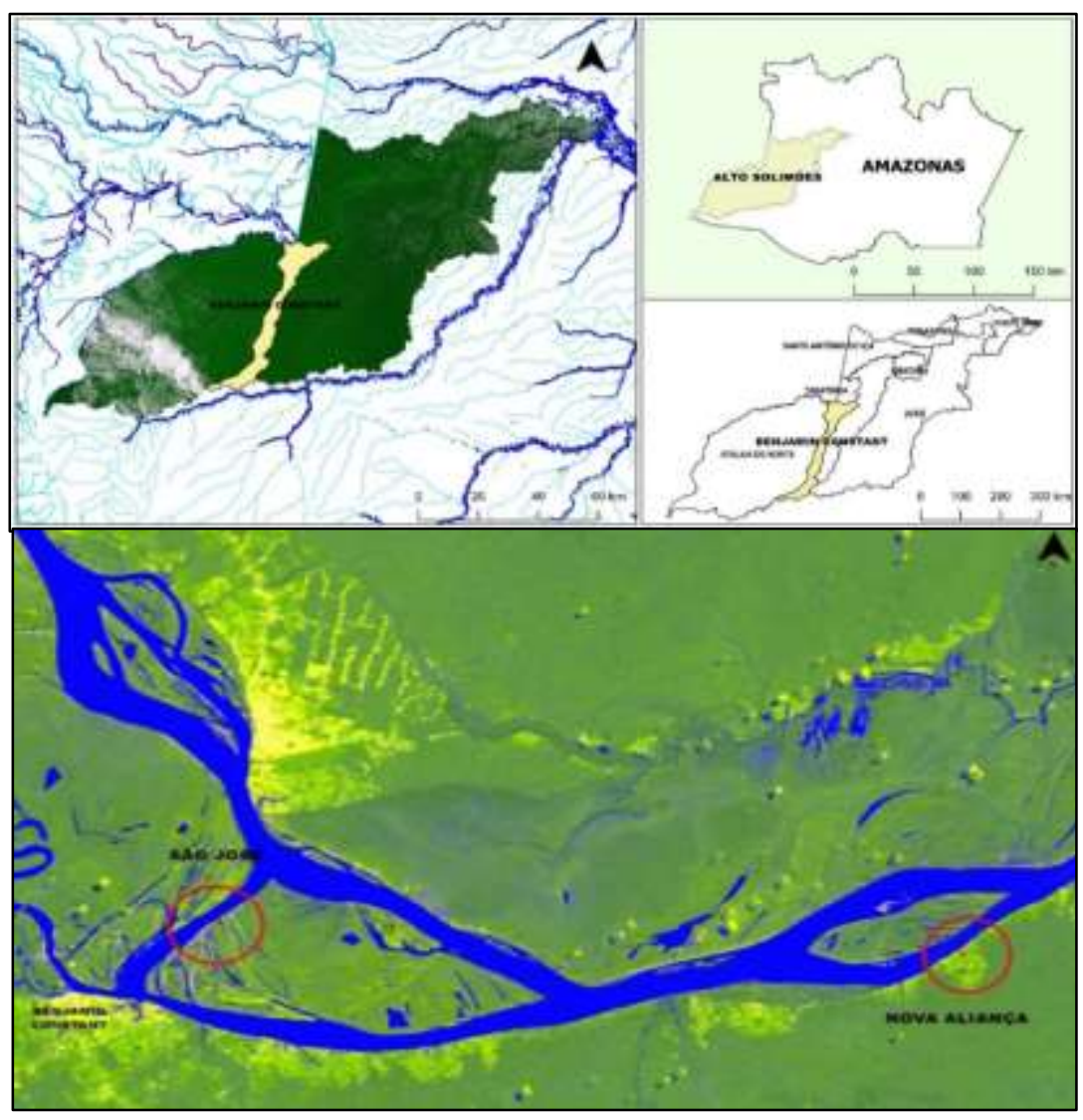

Fonte: Levantamentos de campo (2016 - 2019); INPE (2018); IBGE (2018).

A comunidade São José, na várzea, pertence ao Projeto de Assentamento Agroextrativista (PAE) para fins de reforma agrária denominado Ilha do Aramaçá (Souza, 2018; Martins, 2016). O acesso à comunidade se dá pelo Rio Solimões e cerca de 25 famílias residem nesta comunidade, tendo como base econômica a agricultura familiar o extrativismo do pescado e a diversificação das atividades nos agroecossistemas familiares. 
A comunidade Nova Aliança, está localizada em um platô de terra firme e ocupa uma área de 375 ha. As áreas de uso das famílias desta comunidade fazem parte do processo de identificação da Terra Indígena denominada SURURUÁ, ocupada por grupos das etnias Cocama e Ticuna. O rio Solimões é a única via de acesso com a sede de Benjamin Constant. A agricultura, a pesca e o extrativismo vegetal são os meios essenciais para a sobrevivência das 74 famílias.

As metodologias específicas de análise utilizadas para compreender sobre os solos dos agroecossistemas das comunidades de São José e Nova Aliança, foram aprimoradas e adaptadas de Noda S. (2000), Coelho et. al. (2005), Fermin (2019), dentre outros autores, desenvolvidas com base em casos amazônicos.

As áreas de coleta foram definidas a partir dos agroecossistemas estudados, em áreas de quintal, roça, capoeira e florestas. A motivação desta análise foi alicerçada na perspectiva de se observar e conhecer a fertilidade dos solos nas comunidades pesquisadas, ressaltando a importância das práticas de manejo dos agricultores nos agroecossistemas para a sustentabilidade ambiental. Para a caracterização das paisagens agroecossistêmicas foram realizadas análises da fertilidade do solo, com o detalhamento das variantes do manejo do solo e as consequentes modificações causadas pela ação dos sujeitos.

A metodologia utilizada para a coleta das amostras de solos foi a estabelecida pela EMBRAPA em 2009. Nas comunidades São José e Nova Aliança as amostras de solo foram coletadas com trado holandês em 03 profundidades diferentes, nos agroecossistemas familiares de 04 agricultores. Nos quintais, nas roças, nas capoeiras e na floresta coletou-se amostras de 0 a 20cm; 20 a $40 \mathrm{~cm} ; 40$ a $60 \mathrm{~cm}$ de profundidade. Para se formar uma amostra composta foram coletadas 04 sub-amostras simples, que misturadas formaram uma única amostra. No final tínhamos 04 amostras compostas em cada unidade de paisagem estudada de cada comunidade. As amostras foram acondicionadas em sacolas plásticas e previamente identificadas para o transporte até o laboratório. A amostragem ocorreu em acordo com o delineamento em blocos casualizados (DIC) e os locais de coletas foram escolhidos aleatoriamente por sorteio.

No laboratório do Instituto Natureza e Cultura - INC/UFAM, primeiramente as amostras foram colocadas para secar e quando secas destorroadas manualmente, retirando-se cuidadosamente os resíduos vegetais. Esse material seco e destorroado passou por uma peneira com malha fina de 2mm, obtendo-se dessa forma, a terra fina seca ao ar "TFSA" (Curi et al., 1993). Posteriormente, estas amostras foram encaminhadas ao Laboratório de Solos da Universidade Federal do Amazonas em Manaus para análise da fertilidade. A análise estatística dos dados foi realizada utilizando-se softwares livres para tal finalidade. Para avaliar a similaridade entre os solos dos ecossistemas de várzea e terra firme estudados, bem como, entre as diversas formas de uso, foi elaborado um dendrograma a partir da inserção das médias dos atributos químicos em software estatístico livre, que gerou um dendrograma mostrando a existência de similaridade com relação à fertilidade, para as áreas estudadas.

\section{Resultados e Discussão}

Dentro de cada ambiente dos agroecossistemas (floresta, quintal, capoeira e roça), foram avaliadas as condições químicas dos solos para que se tivesse um panorama geral com relação às práticas de manejo dos agricultores e a conservação. Na comunidade São José, na qual o solo é submetido a alagação sazonalmente, foram observados solos da classe dos Gleissolos e Neossolos fúlvicos, nas cores cinza ou marron, tipos estes também relatados por Fermin (2019), Martins (2016) e Lima et al. (2006). Estes solos, característicos de várzeas, são dinâmicos, variando constantemente no que diz respeito a sua fertilidade natural, porém, mal drenados, impondo certas emergências aos moradores que necessitam desenvolver estratégias para sobrevivência e permanência no lugar. Já na comunidade Nova Aliança, área de terra firme, foram observados solos da classe dos Argissolos e Cambissolos, nas cores vermelho ou laranja, também relatados por Fermin (2019), Dácio (2017), Soares (2007); Fidaalgo, E.C.C. et al. (2005) e Coelho et al. (2005). 
Com base nos dados dispostos na Tabela 1, abaixo, podemos perceber uma grande variação da fertilidade do solo quando comparamos os dois tipos de ecossistemas (várzea e terra firme), assim como, os componentes dos agroecossistemas (quintal, roça, capoeira e floresta) e as profundidades avaliadas $(0-20,20-40,40-60 \mathrm{~cm})$.

Tabela 1. Valores médios de nutrientes dos solos das florestas, dos quintais agroflorestais, roças e capoeiras dos agroecossistemas das comunidades de São José e Nova Aliança, Benjamin Constant - AM.

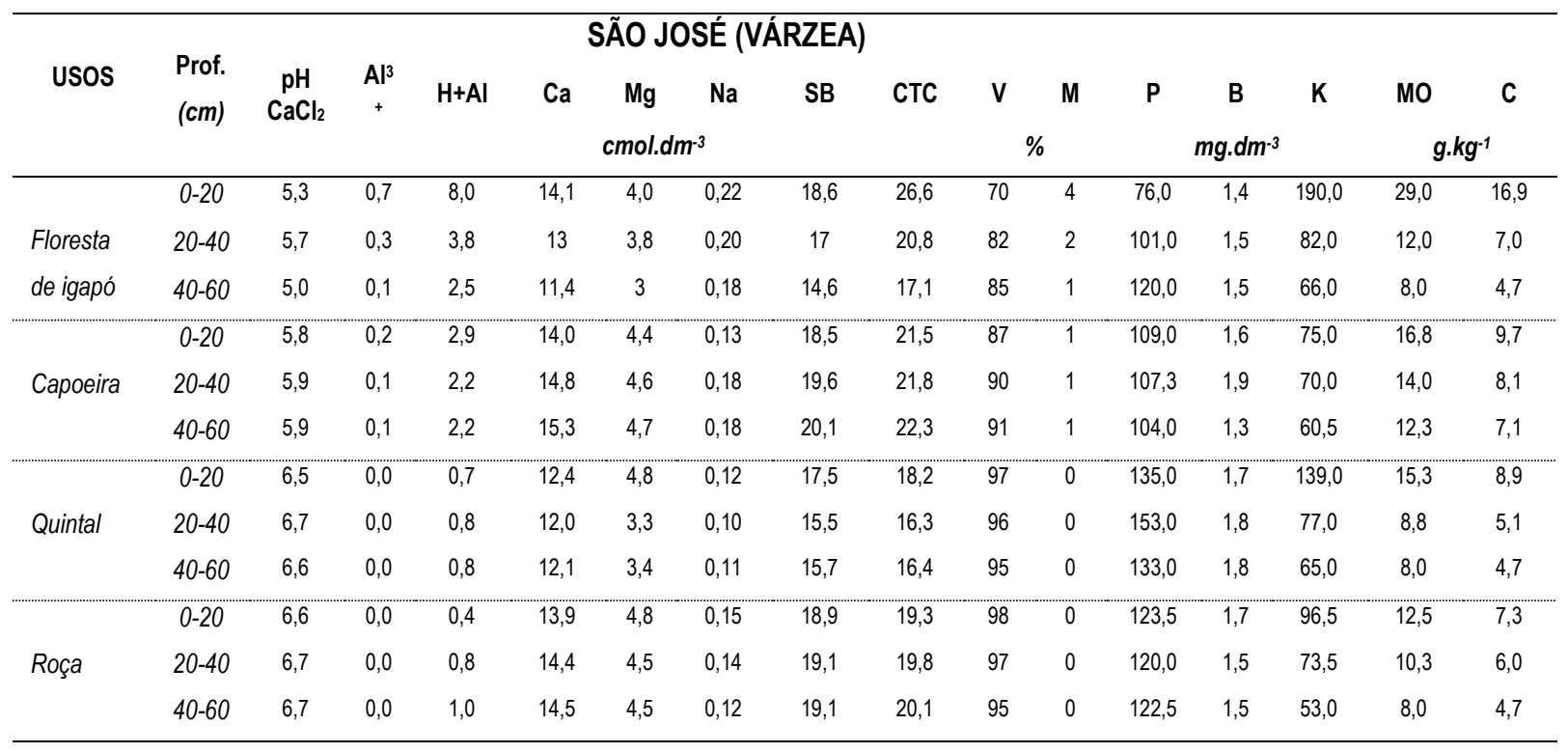

\section{NOVA ALIANÇA (TERRA FIRME)}

\begin{tabular}{|c|c|c|c|c|c|c|c|c|c|c|c|c|c|c|c|c|}
\hline USOS & $\begin{array}{l}\text { Prof. } \\
(\mathrm{cm})\end{array}$ & $\underset{\mathrm{CaCl}^{2}}{\mathrm{pH}}$ & $\begin{array}{c}\mathrm{Al}^{3} \\
+\end{array}$ & $\mathrm{H}+\mathrm{Al}$ & $\mathrm{Ca}$ & \multicolumn{2}{|c|}{ 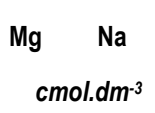 } & SB & СTC & V & M & \multicolumn{3}{|c|}{$\begin{array}{lcc}\text { P } & \text { B } \\
& \text { Kg.dm } & \end{array}$} & \multicolumn{2}{|c|}{ MO $\quad$ C } \\
\hline \multirow{3}{*}{ Floresta } & $0-20$ & 4,1 & 3,6 & 15,0 & 5,5 & 3,6 & 0,11 & 9,4 & 24,4 & 39 & 28 & 11,0 & 0,8 & 128,0 & 43,0 & 25,0 \\
\hline & $20-40$ & 4,0 & 4,2 & 18,5 & 6,3 & 2,4 & 0,12 & 9,0 & 27,5 & 33 & 32 & 10,0 & 0,8 & 128,0 & 46,0 & 26,7 \\
\hline & $40-60$ & 3,9 & 6,1 & 20,5 & 5,1 & 2,0 & 0,12 & 7,5 & 28,0 & 27 & 45 & 9,0 & 0,4 & 148,0 & 37,0 & 21,5 \\
\hline \multirow{3}{*}{ Capoeira } & $0-20$ & 4,1 & 2,1 & 10,0 & 3,2 & 0,9 & 0,08 & 4,3 & 14,3 & 29 & 34 & 5,0 & 0,8 & 96,0 & 25,5 & 14,8 \\
\hline & $20-40$ & 4,0 & 3,0 & 12,1 & 4,6 & 1,6 & 0,03 & 6,3 & 18,4 & 34 & 36 & 3,5 & 0,5 & 57,0 & 20,0 & 11,6 \\
\hline & $40-60$ & 4,0 & 2,6 & 17,0 & 3,8 & 0,7 & 0,05 & 5,3 & 21,6 & 21 & 40 & 4,3 & 0,4 & 56,5 & 19,8 & 11,5 \\
\hline \multirow{3}{*}{ Quintal } & $0-20$ & 4,4 & 4,5 & 6,4 & 4,5 & 1,9 & 0,20 & 10,7 & 17,1 & 63 & 5 & 17,8 & 0,4 & 120,0 & 33,0 & 19,2 \\
\hline & $20-40$ & 4,0 & 3,7 & 13,9 & 4,3 & 1,3 & 0,09 & 5,7 & 19,7 & 29 & 40 & 20,8 & 0,5 & 72,5 & 20,5 & 11,9 \\
\hline & $40-60$ & 3,9 & 4,2 & 15,4 & 4,7 & 1,8 & 0,10 & 6,6 & 22,0 & 31 & 39 & 31,8 & 0,4 & 63,0 & 18,0 & 10,5 \\
\hline \multirow{3}{*}{ Roça } & $0-20$ & 4,1 & 1,9 & 8,3 & 4,9 & 2,3 & 0,07 & 7,4 & 15,7 & 47 & 20 & 8,3 & 0,5 & 90,5 & 22,8 & 13,2 \\
\hline & $20-40$ & 4,0 & 3,3 & 13,4 & 3,9 & 1,2 & 0,04 & 5,1 & 18,5 & 28 & 38 & 5,0 & 0,4 & 57,0 & 14,8 & 8,6 \\
\hline & $40-60$ & 3,9 & 5,1 & 15,2 & 3,7 & 1,2 & 0,04 & 5,0 & 20,2 & 26 & 51 & 3,8 & 0,5 & 46,0 & 13,8 & 8,0 \\
\hline
\end{tabular}

Fonte: Coleta de Campo dos autores $\left(2017\right.$ - 2019). Legenda: $\mathrm{pH}$ : acidez ativa; $\mathrm{Al}^{3+}$ : alumínio trocável; $\mathrm{H}+\mathrm{Al}^{3+}$ : acidez potencial; $\mathrm{Ca}^{2+}$ : cálcio trocável, $\mathrm{Mg}^{2+}$ : trocável, $\mathrm{Na}$ : sódio trocável, $\mathrm{K}$ : potássio disponível; $\mathrm{P}$ : fósforo trocável; $\mathrm{B}$ : boro disponível; S: soma de base; T: capacidade de troca de cátions a pH 7,0, t: capacidade de troca efetiva; V: percentagem de saturação por bases; m: percentagem de saturação por alumínio; C: carbono; M.O.: Matéria Orgânica.

De acordo com os padrões de fertilidade de solos estabelecidos por Cochrane e colaboradores (1985), os resultados apresentados na tabela, mostram que os solos da comunidade São José (várzea) são menos ácidos que os de Nova Aliança. O pH dos solos de São José nos ambientes dos quintais e das roças se mostrou básico e o alumínio trocável tendeu a zero, com pequenas exceções e variações nas áreas de floresta e capoeira. Por se mostrarem solos com menos acidez, os solos de várzea não precisam de medidas para a correção do pH nos componentes de produção dos agroecossistemas. Os agricultores de São José não lançam mão de estratégias para a correção do solo quanto a acidez, pois tem o conhecimento de que a dinâmica vivenciada sazonalmente 
nos processos de cheia e vazante conferem aos solos da comunidade características distintas quanto a essa necessidade, devido a isso, eles mesmo relatam em seus discursos:

“A terra é perfeitinha [...], do jeito que Deus nos deu, não precisa tirar nem pôr nada (A.P., 67 anos, São José)”.

Em Nova Aliança (terra firme), houve muita similaridade com relação a acidez do solo nos ambientes de floresta, capoeira, quintais e roças, ou seja, todos os ambientes apresentaram reação fortemente ácida (pH inferior a 5,0), resultado esse ainda potencializado pela associação com o alumínio trocável $\left(\mathrm{Al}^{3+}\right)$. Soares em 2007, na mesma comunidade, encontrou solos extremamente ácidos. As variações observadas para os níveis de acidez no solo, obedecem a uma lógica inversa da disponibilidade de nutrientes essenciais, ou seja, onde os menores níveis de cálcio, magnésio e potássio são encontrados é onde o alumínio trocável apresenta-se em níveis mais elevados (Machado, 2016). Solos como os das terras firmes, de Nova Aliança, formados sob condições de altas precipitações e boa drenagem são geralmente ácidos, devido a lixiviação dos cátions solúveis e consequente substituição por outros cátions menos solúveis como o alumínio (Rodrigues et al., 2017), tornando-se fator limitante no estabelecimento dos cultivos agrícolas.

Os resultados obtidos nas paisagens agroecossistêmicas avaliadas, com vista a estimar os efeitos provocados pelo

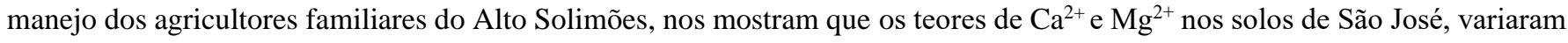

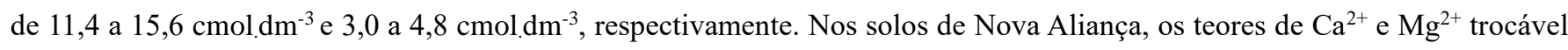
variaram de 3,2 a $5,1 \mathrm{cmol}_{\mathrm{dm}}^{-3}$ e 0,7 a $3,6 \mathrm{cmol}_{\mathrm{dm}}^{3}$, respectivamente, estes valores enquadram-se como medianos a muito alto seguindo os parâmetros estabelecidos por Cochrane et al. (1985) e foram descritos de forma similar por Noda S. (2000), Lima et al. (2006) e Coelho et al. (2005), em várzea e terra firme, no mesmo município de realização desta pesquisa (Benjamin Constant - AM). A partir do resultado da análise química apresentado na tabela, podemos observar ainda que os solos das paisagens de várzea (São José), possuem elevados teores de cátions trocáveis, especialmente cálcio, magnésio, sódio e alumínio, quando comparados aos solos da terra firme (Nova Aliança). Assim como, reação menos ácida, níveis mais elevados de nutrientes e menores teores de alumínio trocável.

Ao observarmos os valores na Tabela 1, percebemos que em São José os teores de $\mathrm{Ca}^{2+}$ e $\mathrm{Mg}^{2+}$ apresentaram-se de forma análoga para os ambientes da floresta, capoeira e roças. Em Nova Aliança os teores de cálcio e magnésio na floresta foram superiores aos teores dos demais ambientes. Ainda assim, nas duas comunidades, os teores obtidos para as áreas de roça foram elevados e de acordo com Magalhães (2011), citado por Fermin (2019), no caso dos solos de várzea, apesar de serem ricos em bases como $\mathrm{Ca}$ e $\mathrm{Mg}$, pois recebem anualmente sedimentos Andinos, o que os rejuvenesce, e mesmo com os inúmeros estudos ressaltando a não necessidade de aplicação de fertilizantes, alguns agricultores, ainda os utilizam. O inverso ocorre nas áreas de terra firme, onde sem o aporte de nutrientes provenientes da floresta, quando da conversão do solo em roças, tendem a perder esses cátions, devido ao constante intemperismo (lixiviação) e retirada da vegetação, tornando a fertilização uma necessidade constante e prática usual dos agricultores.

Com relação aos teores de potássio (K) observou-se uma variação de 46 a 190 mg.dm ${ }^{-3}$, nos dois ecossistemas estudados. De maneira geral, observa-se que os teores de potássio são sempre mais elevados nos horizontes superficiais, independente do uso, isto ocorre devido, a disponibilidade de potássio ser diretamente proporcional à ciclagem de nutrientes (FERMIN, 2019). Nos solos das duas comunidades, os teores de potássio nas florestas de várzea e terra firme foram superiores às demais áreas, sendo seguidos pelos elevados teores nos quintais agroflorestais. Os valores mais baixos foram observados nas áreas de roça, embora nos horizontes superficiais, o valor seja muito próximo dos demais ambientes. O potássio, conforme Machado (2016), é um nutriente que desempenha papel metabólico indispensável no desenvolvimento das plantas e, assim como os demais nutrientes essenciais, seu baixo suprimento condiciona negativamente a produtividade dos cultivos. 


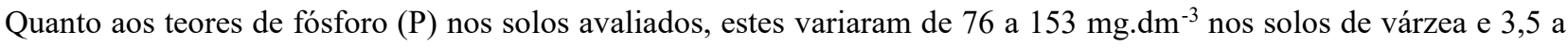
$31,8 \mathrm{mg} \cdot \mathrm{dm}^{-3}$ na terra firme. Tanto na várzea como na terra firme, as maiores concentrações de fósforo foram observadas nos quintais agroflorestais. Machado (2016) e Pinho et al. (2011) afirmam que os níveis de P estão relacionados ao histórico da ocupação humana dos agroecossistemas, ou seja, por consequência, a concentração de P aumenta de acordo com a idade dos quintais, diferentes padrões de manejo ao longo do tempo, descarte de material orgânico e introdução de espécies.

O Sódio trocável ( $\mathrm{Na}$ ) nas áreas de várzea variou de 0,11 a $0,22 \mathrm{cmol}_{\mathrm{dm}}^{-3}$. E nas áreas de terra firme variou de 0,03 a $0,20 \mathrm{cmol}_{\mathrm{dm}}{ }^{-3}$. O sódio é um componente presente na determinação da CTC e da soma das bases, portanto deve ser determinado. Em São José as maiores concentrações deste elemento foram encontradas nas áreas de floresta, quintais e roças. Em Nova Aliança, os quintais e as florestas apresentaram os maiores teores de sódio, considerando-se que os quintais agroflorestais na comunidade são tão adensados e diversos como as áreas de floresta, é compreensível que alguns nutrientes tenham seus teores nos quintais bem próximo ou superiores aos teores das áreas de floresta.

Os valores de soma de base (SB) e de saturação por bases (V) foram maiores nos solos de várzea, assim como a saturação por alumínio (m) nesse mesmo ecossistema foi menor. O processo inverso ocorreu nos solos de terra firme avaliados onde a soma (SB) e a saturação por bases (V) foram menores e a saturação por alumínio foi maior (m). Os solos da comunidade São José, podem ser classificados como eutróficos (férteis), onde a saturação por bases (V) é maior ou igual a 50\%. Os solos de Nova Aliança, podem ser classificados como distróficos (pouco férteis) onde a saturação por bases (V) é menor que 50\% (Ronquim, 2010), ainda assim no caso dos solos de terra firme (Nova Aliança) avaliados nesta pesquisa, mesmo sendo considerados ácidos e pobres em nutrientes, ainda possuem maior riqueza de nutrientes em comparação aos solos mais bem drenados da parte oriental da Amazônia. de acordo com Lima et al. (2006).

O Boro (B) foi o único micronutriente avaliado, devido a uma necessidade dos próprios agricultores familiares com relação aos plantios de maracujá na comunidade São José. Segundo os mesmos e de acordo com a assistência técnica dos órgãos governamentais estaduais, o cultivo do maracujá em grande parte das áreas de roça, exige do solo uma maior demanda deste nutriente para o desenvolvimento das plantas e uma boa produção dos frutos. Em suas percepções, após anos de plantio do maracujá em suas roças eles revelam:

“Eu não vou mais plantar maracujá não, pois ele chupa os nutriente tudinho do solo. Eu vou plantar é banana, pois ela aduba muito (J.S.N., 55 anos, São José)".

Com os plantios de maracujá em diversas propriedades em São José, muitos dos agricultores lançaram mão da aplicação de fertilizantes a base de boro, influenciando nos resultados encontrados nesta pesquisa. Em São José as maiores concentrações de boro foram encontradas nas capoeiras, nas roças e quintais, sendo estes teores superiores duas vezes mais que os encontrados na terra firme de Nova Aliança.

Com relação aos teores de carbono nos ecossistemas avaliados pode-se observar que foram superiores nas florestas, capoeiras e quintais e inferiores nas áreas de roças. Os baixos teores de C nas áreas de roça têm relação com o cultivo de espécies anuais exigindo a canalização de recursos como: água, luz e nutrientes, para o processo produtivo. Como nessas áreas toda a vegetação é removida, interrompendo o processo natural da ciclagem de nutrientes a partir da decomposição do material orgânico que cai das árvores, como ocorrem na floresta, capoeira ou quintal (Noda S.N., 2000). Observou-se também que os teores de Carbono são maiores nos solos de terra firme (Nova Aliança) nos ambientes com todos os usos. Na várzea os teores de Carbono são menores pois, com o processo de alagação constante ocorre sempre a retirada de matéria orgânica do solo, fazendo com que o carbono, proveniente da decomposição da matéria orgânica seja inferior neste ecossistema. 
Partindo do carbono podemos inferir sobre os teores de matéria orgânica nas áreas avaliadas. Segundo Machado (2016) o teor de matéria orgânica relaciona-se diretamente com a fertilidade, pois promove a melhoria da capacidade de retenção de água e nutrientes, sendo essencial para manter os estoques de nutrientes nos solos.

As concentrações de matéria orgânica observadas, sugerem que o uso de estratégias de manejo do solo pelos agricultores familiares amazônicos da várzea e da terra firme, como o período do "descanso" pelo pousio das áreas, o deixar encapoeirar e a conversão de áreas em quintais agroflorestais ou sítios, contribuem para a manutenção do sistema ambiental em que estão inseridos. Desta forma, a fertilidade dos solos avaliados nos revela que essas práticas de manejo, assim como, o uso dos componentes e paisagens agroecossistêmicas devem estar sempre em consonância com o ambiente, visando a conservação como processo norteador e direcionador de todas as atividades de ocupação e manejo dos solos de São José e Nova Aliança, como bens comuns que são.

Para avaliar a similaridade entre os solos dos ecossistemas de várzea e terra firme estudados, bem como, das diversas formas de uso, foi elaborado um dendrograma a partir da inserção das médias dos atributos químicos em software estatístico, livre (Figura 2). O dendrograma mostra claramente que a similaridade da fertilidade do solo para as áreas estudadas foi definida pela variabilidade das concentrações dos atributos químicos analisados. $\mathrm{Na}$ análise do dendrograma de similaridade no conjunto das profundidades (até $60 \mathrm{~cm}$ ), considerando-se os atributos químicos dos solos percebe-se a formação de dois grupos distintos. O grupo A, com os solos de terra firme da comunidade Nova Aliança e seus usos pelos agricultores familiares nos agroecossistemas. E o grupo B, com os solos da comunidade São José, com os solos de várzea e seus usos pelos agricultores familiares do Alto Solimões.

Dentro de cada grupo foram formados três subgrupos, sendo que alguns são similares e outros são dissimilares quanto aos teores de nutrientes, carbono e acidez de seus solos. Os solos de capoeira e roça nos dois ecossistemas (várzea e terra firme) se mostraram bastante similares quanto aos teores de nutrientes. Por conseguinte, estes grupos formados por roças e capoeiras (a1 e b1) são similares aos quintais agroflorestais avaliados nas duas comunidades quanto aos teores determinados e dispostos na Tabela 1 anterior.

Figura 2. Dendrograma das amostras de solo agrupadas quanto à fertilidade, em áreas de floresta, capoeira, roça e quintal nas comunidades de São José e Nova Aliança.

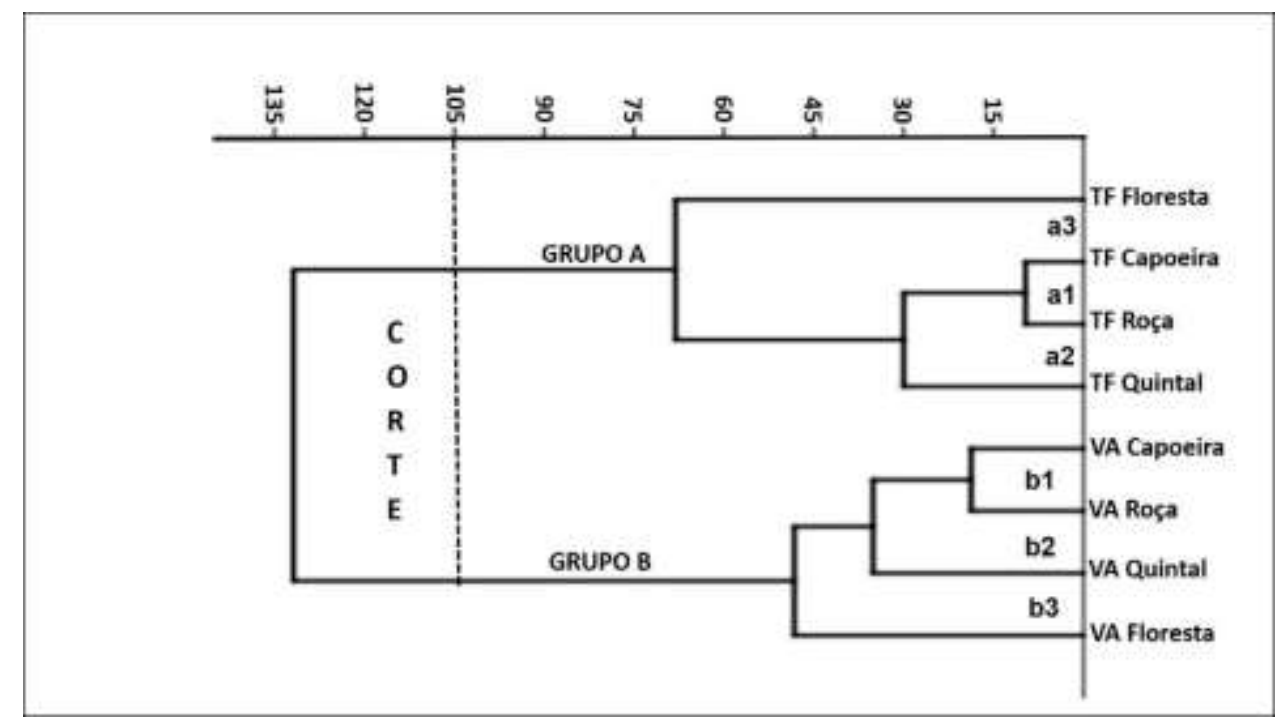

Fonte: Coleta de Campo dos autores (2017 - 2019). Legenda: TF = terra firme (Comunidade Nova Aliança); VA = várzea (Comunidade São José). 
O grupo mais dissimilar foi o formado pela floresta em comparação com os demais sistemas de uso nos agroecossistemas estudados, pois como já avaliado anteriormente, a floresta com relação a maioria dos teores de nutrientes e demais índices, foi a mais fértil e estável no tocante aos atributos químicos dos solos, isto devido ao aporte de nutrientes existente.

\section{Considerações Finais}

Em São José, os agricultores, moradores das várzeas e das margens dos rios, aprenderam ao longo de gerações, um modo de vida, cuja convivência com o sistema ambiental ocorre em consonância com a dinâmica do pulso das águas. Suas práticas de ocupação do solo revelam a conservação por meio da interação com o ambiente, necessário à sua sobrevivência.

Desta forma, o sistema de manejo e uso do solo realizado pelos agricultores familiares de São José e Nova Aliança, demonstram não condicionar o solo a qualquer tipo de exaustão permanente de seus nutrientes minerais, devido adoção de práticas sustentáveis (pousio, encapoeiramento, introdução de espécies e conversão em quintais/sítios) no uso do solo aliadas às atividades de geração de renda e conservação ambiental.

Assim sendo, as comunidades apresentam modelos de conservação do sistema ambiental, a partir da manutenção e reprodução de seus modos de vida, nos agroecossistemas e em seus fatores de produção. Essa dinâmica entre os agricultores familiares, agroecossistemas, uso e manejo dos solos, evidencia a existência de sistemas complexos de interação, circularidade e complementação que corroboram para a formação, transformação e etnoconservação das paisagens amazônicas.

\section{Referências}

Brandão, J. C. M. (2016). Perdurabilidade da Agricultura Familiar no Projeto de Assentamento Vila Amazônia. Tese de Doutorado em Ciências do Ambiente e Sustentabilidade na Amazônia - Universidade Federal do Amazonas. Orientador: Hiroshi Noda e Coorientadora: Sandra do Nascimento Noda. 817p.

Cochrane, T. T., Sanchez, L. G., Azevedo, L. G. \& Carver, C. L. (1985). Land in Tropical America. 1, CIAT, Cali, Colombia and EMBRAPA, Planaltina, D.F., Brazil.

Coelho, M. R. (2005). Solos das áreas-piloto do Projeto BiosBrasil (Conservation and Sustainable Management of Below Ground Biodiversity: Phase I), Município de Benjamim Constant, Estado do Amazonas. Maurício Rizzato Coelho ... [et al.]. Boletim de pesquisa e desenvolvimento - Embrapa Solos, Rio de Janeiro.

Curi, N., Larach, J.O.I., Kampf, N., Moniz, A.C. \& Fontes, L.E.F. (1993). Vocabulário de ciência do solo. 90p.

Dácio, A. I. C. (2017). Segurança alimentar e conservação nos agroecossistemas do Alto Solimões, Amazonas. Tese de Doutorado em Ciências do Ambiente e Sustentabilidade na Amazônia - Universidade Federal do Amazonas.

EMBRAPA (2009). Manual de Análises Químicas de Solos, Plantas e Fertilizantes. (2a ed.), 627 p.

Fermin, M. E. N. (2019). Atributos químicos dos solos de várzea e terra firme, Benjamin Constant/AM. Trabalho de Conclusão de Curso - TCC/MONOGRAFIA. Instituto Natureza e Cultura - INC/UFAM. 36 p.

Fidalgo, E. C. C., Coelho, M. R., Araújo, F. O., Moreira, F. M. S., Santos, H. G., Santos, M. L. M \& Huising, J. (2005). Levantamento do uso e cobertura da terra de seis áreas amostrais relacionadas ao projeto BiosBrasil (Conservation and Sustainable Management of Below-Ground Biodiversith: Phase I), município de Benjamim Constant (AM) - Dados eletrônicos. -- Rio de Janeiro: Embrapa Solos, Boletim de pesquisa e desenvolvimento, ISSN 1678-0892.

IBGE - Instituto Brasileiro de Geografia e Estatística (2010). Censo Brasileiro de 2010: Pesquisa Nacional por Municípios. Rio de Janeiro: IBGE, 2010. Acesso em 04 de Julho de 2018. Disponível em: http://www.ibge.gov.br/home/estatistica/censodemográfico.pdf.

IBGE - Instituto Brasileiro de Geografia e Estatística (2017). Cidades@. Diretoria de Pesquisas - DPE - Coordenação de População e Indicadores Sociais COPIS. Disponível em: http://cidades.ibge.gov.br/xtras/perfil.php?codmun=130060. Acesso em 23/03/2019.

Lima, H. N., Mello, J. W. V., Schaefer, C. E. G.R., Ker, J. C. \& Lima, A. M. N. (2006). Mineralogia e química de três solos de uma topossequência da bacia sedimentar do Alto Solimões, Amazonas Ocidental. R. Bras. Ci. Solo, 30:59-68.

Lima, H. N., Teixeira, W. G. \& Souza, K. W. (2007). Os solos da paisagem da várzea com ênfase no trecho entre Coari e Manaus. IN: comunidades ribeirinhas amazônicas: modos de vida e uso dos recursos naturais. Org.: Fraxe, T. J. P., Pereira, H. S., Witkoski, A. C. Manaus. Editora Edua, 224p.

Machado, D. O. (2016). A agrobiodiversidade de quintais agroflorestais em propriedades agrícolas familiares na BR 174, Ramal do Pau-Rosa, Manaus, AM. Dissertação (Mestrado) --- INPA, Manaus, 86 f.: il.

Magalhães, R. C. (2011) As características físicas, químicas, mineralógicas e hidráulicas do solo e sua susceptibilidade ao processo de Terras Caídas: comunidade do Divino Espírito Santo - Iranduba/AM. Dissertação (Mestrado em Geografia), Faculdade de Ciências Humanas, Universidade Federal do Amazonas, Manaus - AM. 
Research, Society and Development, v. 10, n. 8, e9310816763, 2021

(CC BY 4.0) | ISSN 2525-3409 | DOI: http://dx.doi.org/10.33448/rsd-v10i8.16763

Martins, A. L. U. (2016). Conservação da Agrobiodiversidade: Saberes e Estratégias da Agricultura Familiar na Amazônia. Tese de Doutorado em Ciências do Ambiente e Sustentabilidade na Amazônia - Universidade Federal do Amazonas.

Noda, S. N. (2000). Na Terra como na Água: Organização e Conservação de Recursos Naturais Terrestres e Aquáticos em uma Comunidade da Amazônia Brasileira. 182f. Tese (Doutorado em Ecologia) - Instituto de Biociências, Universidade Federal de Mato Grosso, Cuiabá.

Noda H, Noda S.N., Martins L. H. P., Martins A. L. U. \& Silva A. I. C. (2013). Etnoecologia de paisagens agrícolas nas várzeas na região do Alto Solimões. In.: Noda H, Noda SN, Laques A, Léna P (Orgs.). Dinâmicas socioambientais na agricultura familiar na Amazônia. Manaus/AM: WEGA.

Pinho, R. C., Alfaia, S. S., Miller, R. P., Uguen, K., Magalhães, L. D., Ayres, M., Freitas, V. \& Trancoso, R. (2011). Islands of fertility: Soil improvement under indigenous homegardens in the savannas of Roraima, Brazil. Agroforestry Systems, 81 (3): 235-247. 2011.

Ricoveri G. (2012). Bens comuns versus mercadoria. Editora MULTIFOCO.

Rodrigues, M. R. L., Teixeira, W. G., Barros, M. E. O., Macedo, R. S., Martins, G. C. \& Ferraz, R.D . (2017). Uso do solo e adubação de espécies florestais nas condições edafoclimáticas da Base Petrolífera de Urucu, Coari, AM. $1^{\circ}$ ed Embrapa Amazônia Ocidental, Manaus, AM, 44p.

Ronquim, C. C. (2010). Conceitos de fertilidade do solo e manejo adequado para as regiões tropicais. Boletim de Pesquisa e Desenvolvimento, 8. Campinas/SP. Embrapa Monitoramento por Satélite, 26p.

Schor, T. (2015). Redes, fluxos e abastecimento de comida no Alto Solimões/AM: reflexões sobre o papel das cidades e da produção rural no desenvolvimento local. Terceira Margem Amazônia, 1, 89-109.

Soares, A. E. S. (2007). Análises químicas de nutrientes em áreas com diferentes sistemas de uso da terra no município de Benjamin Constant, Amazonas. Dissertação de Mestrado apresentada ao PPG de Agricultura no Trópico Úmido. Instituto Nacional de Pesquisas da Amazônia - INPA, Manaus, 52p. 